\title{
Dot blot immunochemical and infrared analyses of the adhesive layer applied to the painting Imago Pietatis by Domenico Morone
}

\author{
Cristina Cattò ${ }^{1}$, Valentina Parodi ${ }^{2}$, Alice Chiodelli ${ }^{2}$, Francesca Cappitelli ${ }^{*^{*}}$ (I) and Silvia Bruni ${ }^{3}$
}

\begin{abstract}
Purpose: To investigate the nature of the materials used in the adhesive layer of the Imago Pietatis painting (end of the fifteenth century - beginning of the sixteenth century) by Domenico Morone as a prerequisite for its restoration.

Methods: Micro-FTIR spectra of the animal glue and a polished cross-section were acquired by a Jasco IRT3000 spectrometer, equipped with a $32 \times$ Cassegrain objective. A dot blot immunoassay was used to characterise a minor component of the adhesive layer.

Results: Micro-FTIR was used as an effective diagnostic tool to detect the major component of the adhesive layer and the binder of the paint. Despite the ageing, the complex matrix and the micro-size of the sample, using a dot blot immunoassay, it was possible to quantify $3.7 \pm 2.0 \mathrm{ng}$ of ovalbumin per microgram of sample (corresponding to 0.004 $\pm 0.002 \%$ of the weight).

Conclusions: The findings were in line with conservation practices described in the old treatises, confirming the correct interpretation of the adhesive layer compounds added to the painting and suggesting for the cleaning the use of an anionic water-soluble surfactant highly effective in the removing of proteinaceous materials.
\end{abstract}

Keywords: Dot blot immunochemical analysis, FTIR, Albumin, Animal glue, Painting, Conservation

\section{Findings}

Imago Pietatis belongs to the polyptych of Tregnago, dismembered and partially exhibited in the Museum of Castelvecchio in Verona, Italy. The panel consists of a poplar wood support onto which, without any canvas underneath the paint layer, was laid two layers of preparation based on plaster and glue. The pictorial finishes, rather thin but of great refinement, presented some conservation problems related mainly to the presence of a massive residue of strongly yellowed material, on which

*Correspondence: francesca.cappitelli@unimi.it

${ }^{1}$ Department of Food, Environmental and Nutritional Sciences, Università degli Studi di Milano, via Celoria 2, 20133 Milan, Italy

Full list of author information is available at the end of the article was imprinted the mark of a thin gauze. It was hypothesised that it could have been a glue deposit attributable to an attempted transfer. (This refers to the practice of preserving an unstable painting on a panel by transferring it from its original decayed, worm-eaten, cracked or distorted wood support to canvas or a new panel. This practice has been in place since the eighteenth century; however, nowadays, it has been largely replaced by improved methods of wood conservation). For this painting, no transfer was in the end carried out, but the treatment applied evidently turned into an intervention to consolidate the colour by means of facing. This consists of the adhesion of a protective layer, most often tissue paper, upon the face of a fragile painting to prevent the 
loss of the paint during conservation, or until conservation is performed. The altered material caused both a colour tearing and an aesthetic problem. Samples of those materials, very abundant on the surface, were taken with the aid of a scalpel and under a microscope, only from the surface layer, in order to be subsequently analysed. The purpose of this investigation was to identify a cleaning method that would only remove the altered materials without damaging the original constituents of the panting, in particular, the binder of the pictorial layer.

The characterisation of binders, e.g. proteins, in the works of art is of interest to shed light on the manufacturing techniques used, to detect previous restoration treatments and to plan an adequate cleaning intervention (Giuffrida et al. 2018).

With regard to the analysis of the altered material, micro-FTIR spectra were acquired by a Jasco IRT3000 spectrometer, equipped with a $32 \times$ Cassegrain objective. Minute amounts of sample were placed in a compression diamond cell, and the spectra were obtained by the accumulation of 256 scans, with resolution $4 \mathrm{~cm}^{-1}$. On the basis of the micro-FTIR spectrum (Fig. 1), the adhesive residue was identified as a proteinaceous material. The possibility that the yellowed material could be constituted by a synthetic resin used in previous restorations was thus ruled out. Despite the great similarity of IR spectra of proteinaceous materials, an excellent correspondence could be observed between the bands of the adhesive residue and the characteristics of collagen at $1652,1546,1455,1408,1338,1280,1243,1207,1158$, 1082 and $1035 \mathrm{~cm}^{-1}$ (Belbachir et al. 2009). The corresponding assignments are reported in Additional file 2: Table S1. In particular, the band situated at $1338 \mathrm{~cm}^{-1}$ is especially typical of animal glue, in comparison with other proteinaceous materials derived for example from egg or milk (Price et al. 2014). It could thus be hypothesised that the adhesive was an animal glue, very commonly employed in applying a gauze to paintings in restoration operations.

Aiming to investigate the binders used in the original painting, micro-FTIR spectra were also recorded in reflection mode on a polished cross-section of a blue paint fragment. A blue coloured area was selected (Fig. 2) as in the treatise Il libro dellarte by C. Cennini (1437), the use of glue rather than egg yolk to mix blue colours was reported. This habit had the purpose of avoiding that the redness of the egg yolk modifies the blue colour.

Absorbance spectra were calculated from the experimental ones by the Kramers-Kronig transform. On the basis of the micro-FTIR reflection spectra (Fig. 3), the pigment azurite was identified, thanks to the signals at 1470-1460, 1440-1430 and 970-960 $\mathrm{cm}^{-1}$ (Bruni et al. 1999). On the other hand, it was not possible to recognise with certainty a proteinaceous binder in the very thin colour layer, as the characteristic amide bands are lacking in the $1650-1500 \mathrm{~cm}^{-1}$ range. However, bands due to degradation products were observed. In particular, two peaks at about 1640 and $1320 \mathrm{~cm}^{-1}$ are typical of oxalates

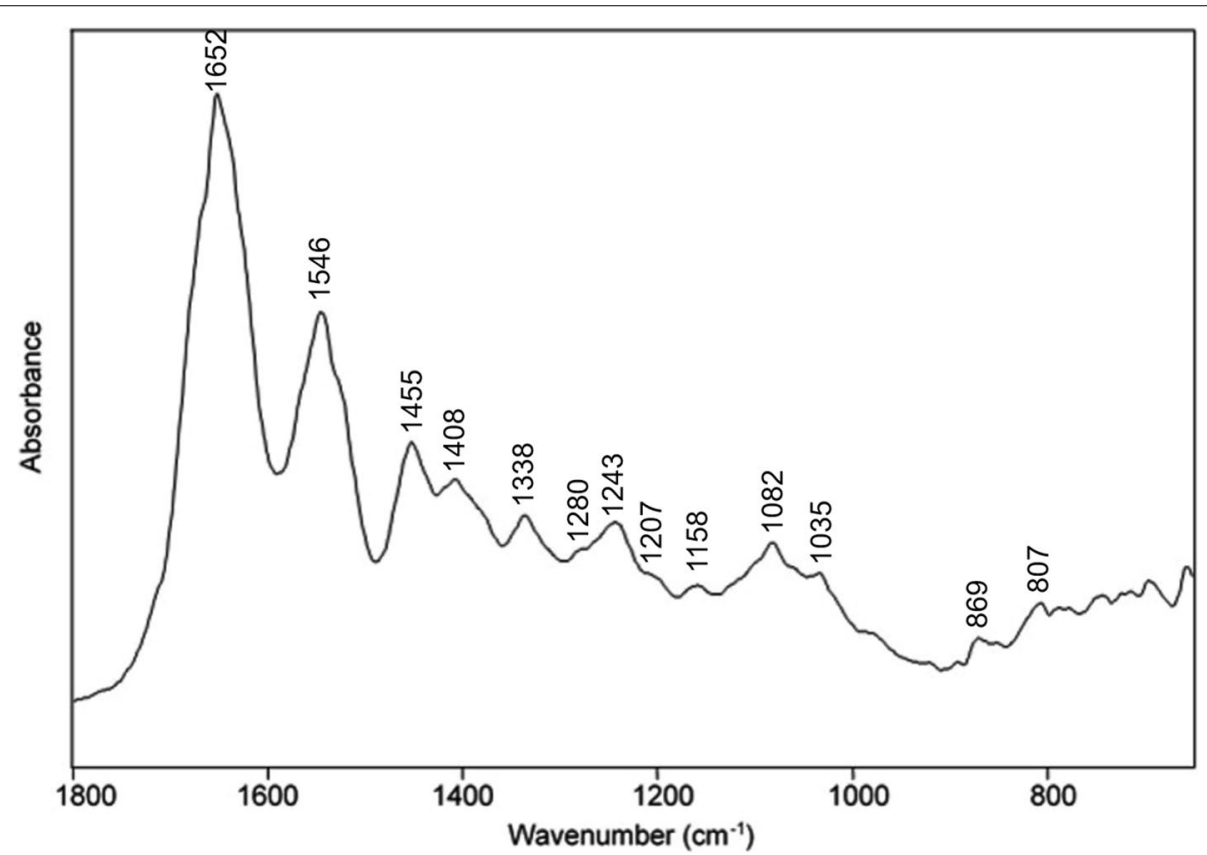

Fig. 1 Micro-FTIR spectrum in the diamond cell of a sample of the yellow residue from the painting surface 


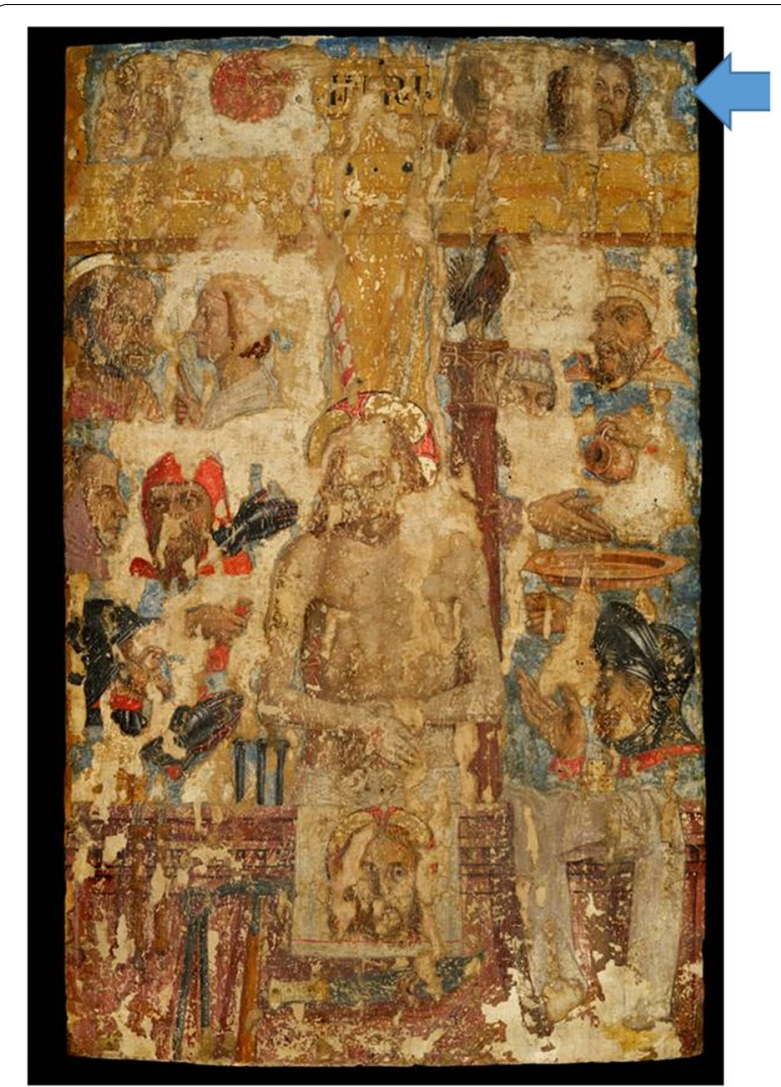

Fig. 2 Morone's painting with the area where the blue paint fragment was taken indicated by an arrow

(Monico et al. 2013). Moreover, a signal at $1580 \mathrm{~cm}^{-1}$ can be assigned to copper carboxylates (Robinet and Corbeil 2003; Otero et al. 2014), coherently with the presence of the copper-based pigment azurite. Finally, three bands around 1560, 1530 and $1512 \mathrm{~cm}^{-1}$ can be tentatively attributed to lead soaps (Garrappa et al. 2021), possibly associated with the use of lead white to lighten the blue colour. In any case, it should be emphasised that the formation of such degradation products has been observed both in oil and egg paintings (Mazzeo et al. 2008; Salvadó et al. 2019). For this reason, as well as for the absence of characteristic bands, a reliable hypothesis could not be formulated concerning the nature of the binder.

Once the collagen was found, the dot blot immunoassay was applied, for the first time on a wood painting, to detect other proteinaceous materials in the adhesive layer not detected by infrared spectroscopy. Ovalbumin was chosen as a target because the usage of egg white (ovoalbumin) as the final layer of paintings is testified in numerous mediaeval treatises.

Paint adhesive samples scraped from the surface of the painting were pooled together, and proteins were extracted by $6 \mathrm{M}$ urea (final concentration of $20 \mathrm{mg} / \mathrm{ml}$ ), followed by overnight vortex mixing and 15 min centrifugation at $11,000 \mathrm{~g}$. Urea is a valuable alternative to extract proteinaceous binders ( $\mathrm{Du}$ et al. 2021). Twelve two-fold serial dilutions $(4.7-2400 \mu \mathrm{g})$ in $6 \mathrm{M}$ urea were prepared from the supernatant and were analysed by the dot blot immunoassay according to Cattò et al. (2017). A polyclonal primary anti-ovalbumin antibody (rabbit antichicken egg albumin whole antiserum, C6534, SigmaAldrich, St. Louis, MO, USA) was used to overcome the barriers common to the traditional analysis of proteinbased artistic materials (protein ageing, small quantity of material, complexity of sample, etc.) as multiple epitopes can be probed (Heginbotham et al. 2006; Gambino et al. 2013). The dried membrane was digitised using the Expression 1680PRO scanner (Seiko Epson Corporation, Amsterdam, Netherlands), and densitometric analyses were performed using the Image Master 1D Elite software (Nonlinear Dynamics Ltd./Amersham Pharmacia Biotech, Cologno Monzese, Italy). A calibration doseresponse four-parameter logistic curve using standard ovalbumin was obtained via GraphPad Prism (GraphPad Software, San Diego, CA, USA). The lower limit of detection (LOD) was $0.6 \pm 0.2 \mathrm{ng}$, while the upper limit of detection (UOD) was found to be $976.4 \pm 173.4 \mathrm{ng}$ (Fig. S1 and Fig. 4) (Cattò et al. 2017). Spots of paint adhesive samples between 300 and $2400 \mu$ g showed densitometric values between the LOD and the UOD, confirming the presence of ovalbumin (Fig. S1 and Fig. 4). The fitting of data with the calibration curve revealed that the sample contained $3.5 \pm 1.0 \mathrm{ng}$ of ovalbumin per milligram of sample, corresponding to $0.0004 \pm 0.0001 \%$ of the weight.

Overall, both the main and minor components should be fully investigated to produce reliable data for a proper conservation treatment. Micro-Fourier transform infrared (FTIR) analyses identified the presence of a proteinaceous glue in the adhesive layer residues, while immunoenzyme assays identified a small amount of egg white. This component, due to sampling performed only at the surface level and to the fact that a proteinaceous binder could not be recognised in the colour layer, could be traced back to a final coating of egg white, a practice handed down in the treatise by $\mathrm{C}$. Cennini (1437) onwards. This hypothesis also seems to be supported by local nineteenth-century sources, which recall that the polyptych was characterised by a surface not altered by yellowed and filmogenic protective films, thus suggesting that the egg white belongs to an original finishing layer, over which the animal glue adhesive was applied in a subsequent restoration intervention.

The restoration work was therefore calibrated in line with the results of the analysis, performing a thinning of 


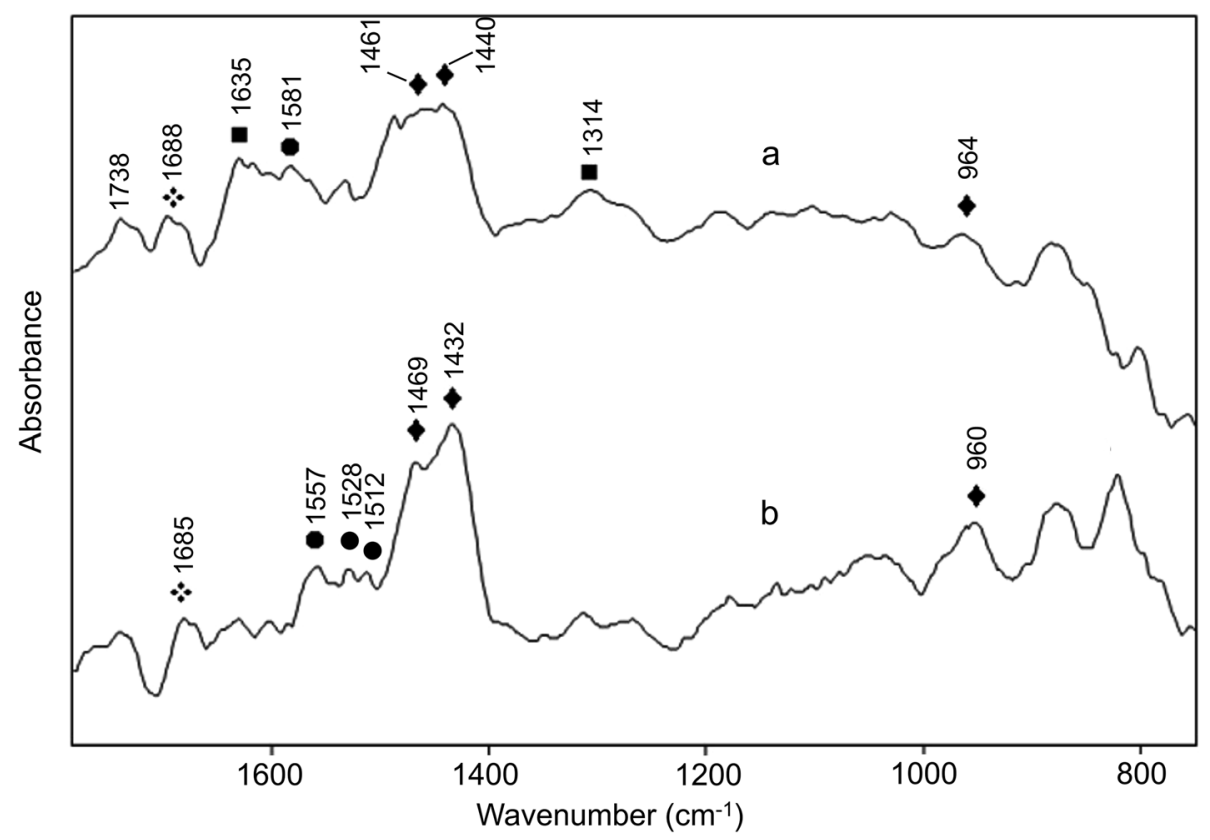

Fig. 3 Reflection micro-FTIR spectra, elaborated by the Kramers-Kronig transform, obtained from two different micro-areas of the colour layer in the

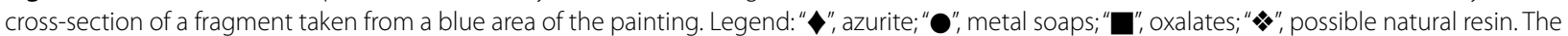
band at about $1740 \mathrm{~cm}^{-1}$ is probably due to the embedding resin

the residues of protein glue by the application of several gels based on coccocollagene, an anionic water-soluble surfactant from collagen and coconut oil fatty acids, highly efficient in removing proteinaceous materials with pHs ranging from 6 to 7 , washed with demineralised water or hydrocarbon mixtures, as the case may require, and capable of lightening the massive glue residues without their total removal.

The diagnostic approach proposed in this article, including also an immunochemical assay used for the first time on a wood painting, in addition to adding knowledge on the history of conservation of the painting being restored, in practical terms opens up an alternative path

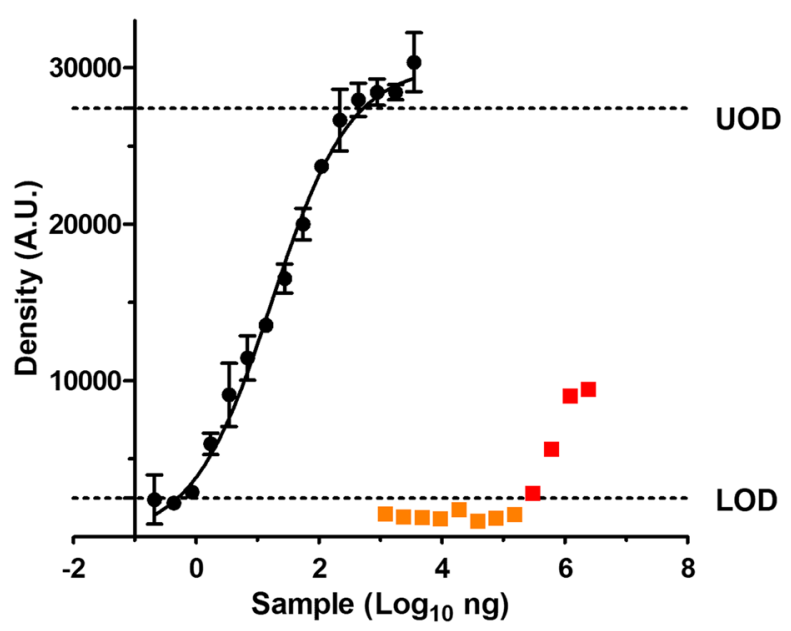

Fig. 4 Density value of standard ovalbumin (black circle) and ovalbumin extracted from paint adhesive sample (orange and red square) against the sample quantity. The logistic dose-response curve of standard ovalbumin and the interval of detection (ID) are reported. UOD, upper limit of detection; LOD, lower limit of detection. Density values of paint adhesive samples included in the ID are reported in red; those not included in the ID are reported in orange 
to traditional diagnostics for the recognition of binders, and adds a critical piece of information for appropriate conservation treatment.

\section{Supplementary Information}

The online version contains supplementary material available at https://doi. org/10.1186/s13213-021-01660-6.

Additional file 1: Figure S1. Dot-blot immunoassay membrane loaded with i) 12 two-fold serial dilutions of ovalbumin extracted from paint adhesive sample (from 2400 to $4.7 \mu \mathrm{g}$, respectively from spot 1 to 12) and ii) 15 two-fold serial dilutions of standard ovalbumin (from $3500 \mathrm{ng}$ to 0.2 ng respectively from spot 1 to 15), used to define the interval of detection. Spot 0 refers to the negative control, loaded with $6 \mathrm{M}$ urea only.

Additional file 2: Table S1. Wavenumbers and assignments of the IR peaks observed for the adhesive residue, identified as animal glue (Sanden et al. 2019).

\section{Acknowledgements}

This work is part of a master's thesis in restoration at the Academy of Fine Arts in Verona. We would like to thank the Castelvecchio Museum of Verona, in particular, the director Dr. Francesca Rossi; the conservators Dr. Ettore Napione and Dr. Antonella Arzone; Dr. M. Vecchiato of the Superintendency of Verona; and the Academy of Fine Arts of Verona, in particular, the director Dr. F. Ronzon and the coordinator of the restoration school Prof. M. Valdinoci. We thank the Castelvecchio Museum of Verona also for the permission to publish the image of Morone's painting.

\section{Authors' contributions}

CC, SB and FC designed the study and wrote the manuscript. VP and AC collected the samples and helped in analysing the data from a conservation point of view. All the authors have read and approved the final version of the manuscript.

\section{Funding}

No funding was received for this research.

\section{Availability of data and materials}

All data generated or analysed during this study are included in this published article.

\section{Declarations}

\section{Ethics approval and consent to participate}

FC is the Editor-in-Chief of Annals of Microbiology.

\section{Consent for publication}

Not applicable.

\section{Competing interests}

The authors declare that they have no competing interests.

\section{Author details}

'Department of Food, Environmental and Nutritional Sciences, Università degli Studi di Milano, via Celoria 2, 20133 Milan, Italy. ${ }^{2}$ Scuola di Restauro, Accademia Belle Arti di Verona, via Montanari 5, 37122 Verona, VR, Italy. ${ }^{3}$ Dipartimento di Chimica, Università degli Studi di Milano, via Golgi 19, 20133 Milan, Italy.

Received: 28 September 2021 Accepted: 2 December 2021

Published online: 07 January 2022

\section{References}

Belbachir K, Noreen R, Gouspillou G, Petibois C (2009) Collagen types analysis and differentiation by FTIR spectroscopy. Anal Bioanal Chem 395:829-837

Bruni S, Cariati F, Casadio F, Toniolo L (1999) Spectrochemical characterization by micro-FTIR spectroscopy of blue pigments in different polychrome works of art. Vib Spectrosc 20:15-25

Cattò C, Gambino M, Cappitelli F, Duce C, Bonaduce I, Forlani F (2017) Sidestepping the challenge of casein quantification in ancient paintings by dot-blot immunoassay. Microchem J 134:362-369

Du J, Zhu Z, Yang J, Wang J, Jiang X (2021) A comparative study on the extraction effects of common agents on collagen-based binders in mural paintings. Herit Sci 9:45

Gambino M, Cappitelli F, Cattò C, Carpen A, Principi P, Ghezzi L, Bonaduce I, Galano E, Pucci P, Birolo L, Villa F, Forlani F (2013) A simple and reliable methodology to detect egg white in art samples. J Biosci 38:397-408

Garrappa S, Hradil D, Hradilová J, Kočí E, Pech M, Bezdička P, Švarcová S (2021) Anal Bioanal Chem 413:263-278

Giuffrida MG, Mazzoli R, Pessione E (2018) Back to the past: deciphering cultural heritage secrets by protein identification. Appl Microbiol Biotechnol 102:5445-5455

Heginbotham A, Millay V, Quick M (2006) The use of immunofluorescence microscopy and enzyme-linked immunosorbent assay as complementary techniques for protein identification in artists' materials. J Am Inst Conserv 45:89-105

Mazzeo R, Prati S, Quaranta M, Joseph E, Kendix E, Galeotti M (2008) Attenuated total reflection micro FTIR characterisation of pigment-binder interaction in reconstructed paint films. Anal Bioanal Chem 392:65-76

Monico L, Rosi F, Miliani C, Daveri A, Brunetti BG (2013) Non-invasive identification of metal-oxalate complexes on polychrome artwork surfaces by reflection mid-infrared spectroscopy. Spectrochim Acta A 116:270-280

Otero V, Sanches D, Montagner C, Vilarigues M, Carlyle L, Lopes JA, Melo M. (2014) Characterisation of metal carboxylates by Raman and infrared spectroscopy in works of art. J Raman Spectrosc 45:1197-1206

Price BA, Pretzel B, Lomax SQ (2014) Infrared and Raman users group spectral database 2007, Philadelphia

Robinet L, Corbeil M-C (2003) The characterization of metal soaps. Stud Conserv 48:23-40

Salvadó N, Butí S, Pradell T, Beltran V, Cinque G, Juanhuix J (2019) Identification and distribution of metal soaps and oxalates in oil and tempera paint layers in fifteenth-century altarpieces using synchrotron radiation techniques. In: Casadio F et al (eds) Metal soaps in art. Cultural heritage science. Springer, Cham, pp 195-210

Sanden KW, Kohler A, Afseth NK, Böcker U, Rønning SB, Liland KH, Pedersen ME (2019) The use of Fourier-transform infrared spectroscopy to characterize connective tissue components in skeletal muscle of Atlantic cod (Gadus morhua L.). J Biophotonics 12:e201800436

\section{Publisher's Note}

Springer Nature remains neutral with regard to jurisdictional claims in published maps and institutional affiliations.

Ready to submit your research? Choose BMC and benefit from:

- fast, convenient online submission

- thorough peer review by experienced researchers in your field

- rapid publication on acceptance

- support for research data, including large and complex data types

- gold Open Access which fosters wider collaboration and increased citations

- maximum visibility for your research: over 100M website views per year

At $\mathrm{BMC}$, research is always in progress.

Learn more biomedcentral.com/submissions 